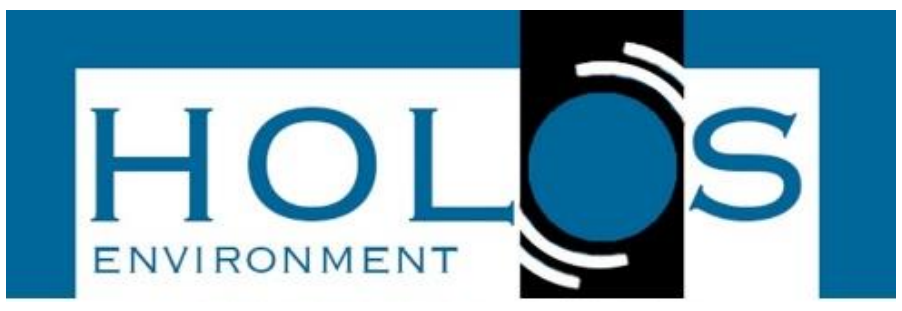

\title{
ESTUDO DE PERCEPÇÕES E AVALIAÇÕES DO CONSUMO DE ÁGUA EM ESCOLAS PÚBLICAS DO RECIFE
}

\section{STUDY OF PERCEPTIONS AND EVALUATIONS OF WATER CONSUMPTION IN PUBLIC SCHOOLS OF RECIFE}

\author{
Juliana Farias Santos de Moraes ${ }^{1}$; Luiz Gustavo Costa Ferreira Nunes ${ }^{1}$; \\ Simone Rosa da Silva ${ }^{1}$
}

Artigo recebido em: 30/03/2018 e aceito para publicação em: 10/05/2019.

DOI: http://dx.doi.org/10.14295/holos.v19i1.12277

Resumo: Com a crescente expansão populacional, a demanda hídrica vem sendo intensificada nos centros urbanos, comprometendo os mananciais responsáveis pelo abastecimento das cidades, cujo comportamento dos usuários apresenta-se diretamente ligado ao consumo e desperdício dos recursos hídricos. Nesse contexto, as tipologias de edificação escolares, geralmente, podem ser enquadradas como grandes desperdiçadoras de água. Desperta-se a importância de incentivar políticas de conservação da água. O presente estudo tem como objetivo avaliar as principais atividades consumidoras de água em duas escolas públicas e identificar o desperdício por ambiente, de acordo com a percepção dos usuários para o uso racional desse insumo. A metodologia consistiu na aplicação de questionários de avaliação e formulários de observação, para determinação do índice de percepção dos usuários (IU) quanto ao uso racional da água de duas escolas públicas estaduais. Os resultados obtidos indicam que, apenas $64,11 \%$ e $64,49 \%$ das atividades consumidoras de água são realizadas de maneira racional, sendo que algumas medidas, como a educação ambiental e a manutenção preventiva de equipamentos hidrossanitários, são propostas com a intenção de promover a otimização do uso da água nos ambientes escolares.

Palavras-chave: Conservação de água. Escolas públicas. Índice de percepção. Uso racional.

Abstract: With increasing population growth, water demand has been intensifying in urban centers, compromising the water supply sources responsible for the cities, whose behavior of users is directly related to the consumption and waste of water resources. In this context, the typologies of school buildings, usually, can be classified as great waste of water, awakening to the importance of encouraging conservation policies. The present study aims to evaluate the main water consumption activities in two public schools and to identify the waste by environment, according to the users' perception for the rational use of this input. The methodology consisted in the application of evaluation questionnaires and forms of observation to determine the users' perception index (IU) of two public schools. The results obtained indicate that, only $64,11 \%$ and $64,49 \%$ of water consuming activities are carried out rationally, thus some measures, such as environmental education and preventive maintenance of hydrosanitary equipment, are proposed with the intetion of promotion the optimization of water use in school environments.

Palavras-chave: Water conservation. Public schools. Perception index. Rational use.

\footnotetext{
1 Universidade de Pernambuco (UPE), Recife, PE. E-mails: (julianafsmoraes@gmail.com, I.gustavo.nunes@hotmail.com, simonerosa@poli.br)
} 


\section{INTRODUÇÃO}

De acordo com Tomaz (2001), o Brasil é considerado um país "rico em água" possuindo uma disponibilidade hídrica de $35.732 \mathrm{~m}^{3} / \mathrm{hab} / \mathrm{ano}$. No entanto, a distribuição dos recursos hídricos no Brasil dá-se de forma bastante heterogênea. Nas bacias junto ao Oceano Atlântico, onde existe a maior concentração populacional, aproximadamente $45,5 \%$, existe a disponibilidade de apenas 2,7\% dos recursos hídricos do país. Em contrapartida, a região Norte do país, que abrange cerca de 5\% da população brasileira, possui aproximadamente $81 \%$ destes recursos (Agência Nacional de Águas - ANA, 2015).

Tundisi (2006) defende a ideia de que a crise da água é ocasionada pela gestão inadequada deste recurso, e que para torná-la mais eficiente, possibilitando a otimização dos usos múltiplos da água e sua conservação, é fundamental uma integração entre o conhecimento científico adquirido e o gerenciamento. Impulsionados por esta problemática, nos últimos anos vem sendo desenvolvidos junto aos prédios públicos Programas de Uso Racional da Água (PURA), buscando algumas alternativas que corroborem com o uso sustentável da mesma. Alguns autores, como Vairavamoorthy e Mansoor (2006), afirmam que a gestão dos recursos hídricos pode ser otimizada quando o público para o qual são destinados torna-se conhecido, sendo de grande importância a percepção dos usuários para o uso consciente, garantindo a qualidade das atividades exercidas.

Para Melo et al. (2014), práticas e técnicas economizadoras de água devem ser aplicadas pela população consumidora, para que seja incentivado o seu uso racional. Assim, por ser um alicerce para a formação dos indivíduos, o ambiente escolar torna-se fortemente recomendado para a aplicação de tais técnicas. Defendem ainda a ideia de que o espaço escolar reúne diversos fatores que possibilitam o emprego de ferramentas de pesquisa para realizar um levantamento do consumo de água e da percepção dos usuários para o uso racional. Pode-se citar como fator, por exemplo, o uso contínuo da água nas dependências escolares devido à permanência diária dos seus usuários, considerando que existam instalações hidrossanitárias em condições satisfatórias mínimas para uso. Por esse motivo, Tomaz (2001, p. 18) afirma que "a economia da água usando a educação pública deverá estar dentro do programa geral de economia de água", por ser um ambiente propício a isso. 
Gonçalves et al. (2005), Nunes (2015), Nunes, Wanderley e Silva (2017), Nunes (2018) e Oliveira e Gonçalves (1999) mostram que nos ambientes escolares o índice de manifestações patológicas apresenta-se alto. Isso ocorre não somente devido à ausência de manutenções preventivas das instalações hidrossanitárias, mas também devido à falta de sensibilização por parte dos usuários no que diz respeito à economia de água. Isso acontece muitas vezes porque não existe a responsabilidade direta com o pagamento das contas de água, uma vez que as escolas analisadas estão enquadradas no setor público (GONÇALVES et al., 2005).

Avaliar o índice de percepção do uso racional (IU) mostra-se uma medida eficaz para identificar as atividades que demandam maior uso de água, possibilitando a aplicação de medidas para otimização do uso deste insumo. Ywashima (2005) desenvolveu uma metodologia que possibilita aferir este índice de percepção conforme a utilização de água nas escolas, possibilitando conhecer a relação entre a conscientização dos usuários e as questões ambientais.

Desta forma, este trabalho propõe elencar as principais atividades consumidoras de água realizadas nas escolas públicas estaduais de Recife para classificá-las de acordo com o desperdício através do índice de percepção dos usuários para o uso racional (IU) e analisar seu histórico de consumo de água, a fim de avaliar o comportamento dos usuários locais quanto à consciência da importância da água.

\section{MATERIAL E MÉTODO}

A metodologia deste trabalho segue as diretrizes de Ywashima (2005), adaptada por Nunes (2015), que sugere estudar os hábitos de consumo de água em escolas públicas através de entrevista estruturada e formulários de observação. Com o intuito de conhecer as escolas previamente selecionadas, foi necessária a realização de visitas para preenchimento de formulários de cadastro, que consistem em perguntas técnicas e administrativas, para conhecimento da infraestrutura e das instalações hidrossanitárias do prédio a ser trabalhado.

Em Recife, as escolas públicas estaduais são enquadradas em quatro tipologias distintas, sendo elas: regular, EREM - Jornada Integral, EREM - Jornada SemiIntegral e Escola Técnica. Nas escolas regulares o foco é o ensino fundamental e o aluno deve cumprir uma carga horária de vinte horas semanais, permanecendo na escola em apenas um turno. 
Nas tipologias EREM e Técnica, o tempo é organizado de maneira que atendam os estudantes em jornada ampliada de aprendizagem e ambas abrangem o ensino médio e, algumas vezes, ensino profissionalizante. Com isso, nas escolas EREM - Jornada Integral e em algumas escolas Técnicas, o aluno deve cumprir uma carga horária de quarenta e cinco horas semanais, funcionando em dois turnos durante toda a semana, com a diferença de que em algumas Escolas Técnicas, são oferecidos cursos de nível profissionalizante. Para as escolas EREM - Jornada Semi-Integral, a carga horária é distribuída em trinta e cinco horas semanais, havendo permanência dos alunos em dois turnos apenas duas ou três vezes por semana.

A coleta de dados das escolas foi realizada em algumas etapas detalhadas abaixo.

i. Uma lista com 180 prédios, localizados no município de Recife, foi fornecida pela Secretaria de Educação do Estado de Pernambuco (SEE) em parceria com a Secretaria de Administração do Estado de Pernambuco (SAD), porém destas, apenas 136 eram de fato prédios escolares. Destes, 60 prédios foram realizadas visitas programadas para aplicação dos cadastros gerais, em que se contabilizaram todos os pontos de consumo de água, bem como a população geral da escola, incluindo funcionários e alunos e as manifestações patológicas verificadas nas instalações hidrossanitárias. Parte da análise destes dados pode ser encontrada em Nunes, Wanderley e Silva (2017). A amostra de escolas a ser analisada neste trabalho foi escolhida a partir dos dados de consumo mensais fornecidos pela concessionária local de abastecimento de água e esgotamento sanitário e de acordo com a proximidade das escolas em relação à Escola Politécnica de Pernambuco.

ii. A segunda etapa do trabalho consistiu na aplicação de questionários de percepção dos usuários quanto ao uso racional da água nas dependências escolares, incluindo professores, funcionários e alunos de algumas turmas. Foram utilizados cinco tipos distintos de questionários, de modo a avaliar a utilização de água nos banheiros, copa e áreas interna e externa das escolas selecionadas. Os modelos dos questionários podem ser obtidos em Nunes (2018). Com base nos dados coletados, foi possível desenvolver uma série de análises estatísticas para determinar como a percepção para o uso racional da água interfere no consumo de cada escola. 
Para estipular parâmetros de comparação quanto ao consumo de água em cada escola, faz-se necessário o cálculo do indicador de consumo através de uma série histórica de consumo mensal fornecido pela concessionária local. Para este trabalho, consideraram-se apenas os dados referentes ao ano de 2015, por serem os dados mais recentes.

Posteriormente, foram calculados os indicadores de consumo de água anual (L/aluno/dia) e os indicadores de percepção dos usuários. Através dos dados de consumo histórico da água, foi possível calcular uma média do consumo anual em cada escola estudada para o ano de 2016, visando a determinação do Índice de Consumo (IC) de cada uma, determinado por Oliveira e Gonçalves (1999) de acordo com a Equação 1. A média exclui o período de férias, que compreende os meses de janeiro, junho, julho e dezembro, pois há variação na população da escola.

$$
\mathrm{IC}=\frac{\mathrm{Cm} \times 1000}{\mathrm{NA} \times \mathrm{Dm}}
$$

\section{Onde:}

IC: indicador de consumo (Litros/Consumidor/dia);

Cm: consumo mensal ( $\left.\mathrm{m}^{3} / \mathrm{mês}\right)$;

NA: número de agentes consumidores; e

Dm: quantidade de dias úteis no referido mês.

Para o cálculo, foram desconsiderados os dias em que não há aula, utilizando a quantidade fixa de 22 dias úteis para todos os meses. O cálculo do IC determina a quantidade de água em litros que cada usuário consome por dia e apresenta-se em função de um agente consumidor específico. Para este trabalho, a amostra de agentes consumidores selecionada foi a de alunos, por se tratar da população mais significativa dos ambientes escolares, conforme adotado por Ywashima (2005), Gonçalves et al. (2005), Nunes (2015), Nunes (2018). Como nas escolas estudadas existem dois tipos de alunos, os que estudam em um e em dois turnos, para tornar as escolas comparáveis com outros estudos, considerou-se que o aluno que estuda em dois turnos contabilize como dois, conforme metodologia proposta por Nunes (2015).

Os questionários para avaliação da percepção foram ajustados por Nunes (2018) e agrupam os usuários de acordo com as atividades consumidoras de água desenvolvidas por cada um, sendo eles: alunos, diretor, professores, monitores, ser- 
ventes, cozinheiros e vigilantes. Para cada grupo de usuários, foram utilizados modelos específicos de questionários, condizendo com a atividade que cada usuário desempenha na escola. $\mathrm{O}$ quadro 1 mostra como foram organizados os questionários aplicados durante as visitas.

\begin{tabular}{l} 
Quadro 1 - Tipos de questionário aplicados aos usuários \\
\begin{tabular}{|c|l|}
\hline Tipo & \multicolumn{1}{c|}{ Destinatários e conteúdo básico dos questionários } \\
\hline A & $\begin{array}{l}\text { Usuário de banheiro - Alunos: Forma de uso das torneiras, válvula de des- } \\
\text { carga, mictórios e chuveiros; Observação do desperdício e/ou perda de água } \\
\text { nos pontos de consumo. }\end{array}$ \\
\hline B & $\begin{array}{l}\text { Usuário de banheiro - Direção, professores e demais funcionários: Forma de } \\
\text { uso das torneiras, válvula de descarga, mictórios e chuveiros; Observação } \\
\text { do desperdício e/ou perda de água nos pontos de consumo. }\end{array}$ \\
\hline C & $\begin{array}{l}\text { Responsável pelo preparo das refeições e limpeza da copa - Cozinheiros: } \\
\text { Descrição do processo de limpeza e preparo das refeições; Observação do } \\
\text { desperdício e/ou perda de água nos pontos de consumo. }\end{array}$ \\
\hline E & $\begin{array}{l}\text { Responsável pela limpeza das áreas externas - Serventes e auxiliares de } \\
\text { serviços gerais: Descrição do processo de limpeza e manutenção nos ambi- } \\
\text { entes externos: áreas de circulação e área comum. }\end{array}$ \\
\hline I & $\begin{array}{l}\text { Responsável pela limpeza das áreas internas - Serventes e auxiliares de } \\
\text { serviços gerais: Descrição do processo de limpeza e manutenção nos ambi- } \\
\text { entes internos: salas de aula e refeitório. }\end{array}$ \\
\hline
\end{tabular} \\
\hline
\end{tabular}

Desta forma, a pontuação dos questionários é distribuída de modo a premiar com maiores valores as atividades que são realizadas de maneira mais consciente, enquanto as atividades que se apresentam mais desperdiçadoras obtém pontuações menores. Com isso, é possível estabelecer o IU de cada ambiente como sendo a razão entre o somatório de pontos obtidos por cada escola e a pontuação total que se pode obter nos questionários multiplicado por 100, como indica a equação 2 . Estes valores são representados no gráfico radar.

$$
\mathrm{IU}_{\text {ambiente }}=\frac{\sum \text { Pontos }}{\sum \text { Pontos máximos }} \times 100
$$

A partir da análise da distribuição de consumo por ambiente observada nas escolas através da metodologia de Ywashima (2005), para cada ambiente foi determinado um fator de correção, conforme Nunes (2015). Esse fator deve ser multipli- 
cado pelo valor do IU obtido em cada ambiente e dividido por 100, como demonstra a equação 3.

Pontos obtidos $=\frac{\mathrm{IU}_{\text {ambiente }}}{100} \times$ Fator $_{\text {ambiente }}$

A última etapa consiste em somar todos os pontos obtidos para que possa ser determinado o índice de percepção da escola, indicado na equação 4.

$\mathrm{IU}_{\text {Escola }}=\sum$ Pontos obtidos

Para compreender os resultados, é importante saber que quanto maior for o índice de percepção verificado, mais consciente é considerado o uso da água. Os resultados obtidos através dos questionários foram organizados e abordados nos próximos tópicos do referente trabalho.

\section{RESULTADOS E DISCUSSÃO}

Das 60 escolas visitadas, duas foram escolhidas por se destacarem pela média do consumo no último ano, sua localização e disponibilidade para a visita, consistindo em escolas de tipologias distintas. Para isso, considerou-se o indicador de consumo médio referente ao ano de 2016, como segue abaixo na Tabela 1.

Tabela 1 - Dados cadastrais referentes às escolas selecionadas

Amostra Tipologia IC médio - 2016

(L/aluno/dia)

Escola $42 \quad$ EREM - Semi-Integral $\quad 43,76$

Escola 82

Regular

5,22

Ao compararmos com outros estudos de indicadores de consumo de água em Recife, apresentados por Nunes (2015) e Soares (2016), que encontram respectivamente 3,9 e 4,9 L/aluno/dia, percebe-se que não há um indicador padrão. As diferenças podem ser justificadas pela tipologia de cada escola, que influenciam nos hábitos de consumo de água. Geralmente, escolas em que os alunos permanecem 
em mais de um turno é preparado um almoço, e o corpo discente utiliza os chuveiros após as aulas de Educação Física.

Enquanto que a Escola 82 possui regime regular com 336 agentes consumidores, a Escola 42 enquadra-se na tipologia EREM - Jornada Semi-Integral, com 677 agentes consumidores. Pode-se, ainda, destacar o fato de a Escola 42 preparar quatro refeições diariamente, enquanto a Escola 82 prepara apenas três. É importante notar que a Escola 42 atende a comunidade, fazendo com que haja uma população flutuante que contribui diretamente com o seu consumo mensal.

Os dados da Escola 42 provavelmente apresentam-se mais elevados em virtude da quantidade de vazamentos e manifestações patológicas verificadas nas instalações hidrossanitárias durante a entrevista realizada, como mostram as Figuras 1 e 2. Contudo, verificou-se, ainda, que os banheiros destinados ao corpo discente encontram-se bastante precários, com vários equipamentos quebrados, contribuindo assim, para uma redução no indicador de consumo da escola.

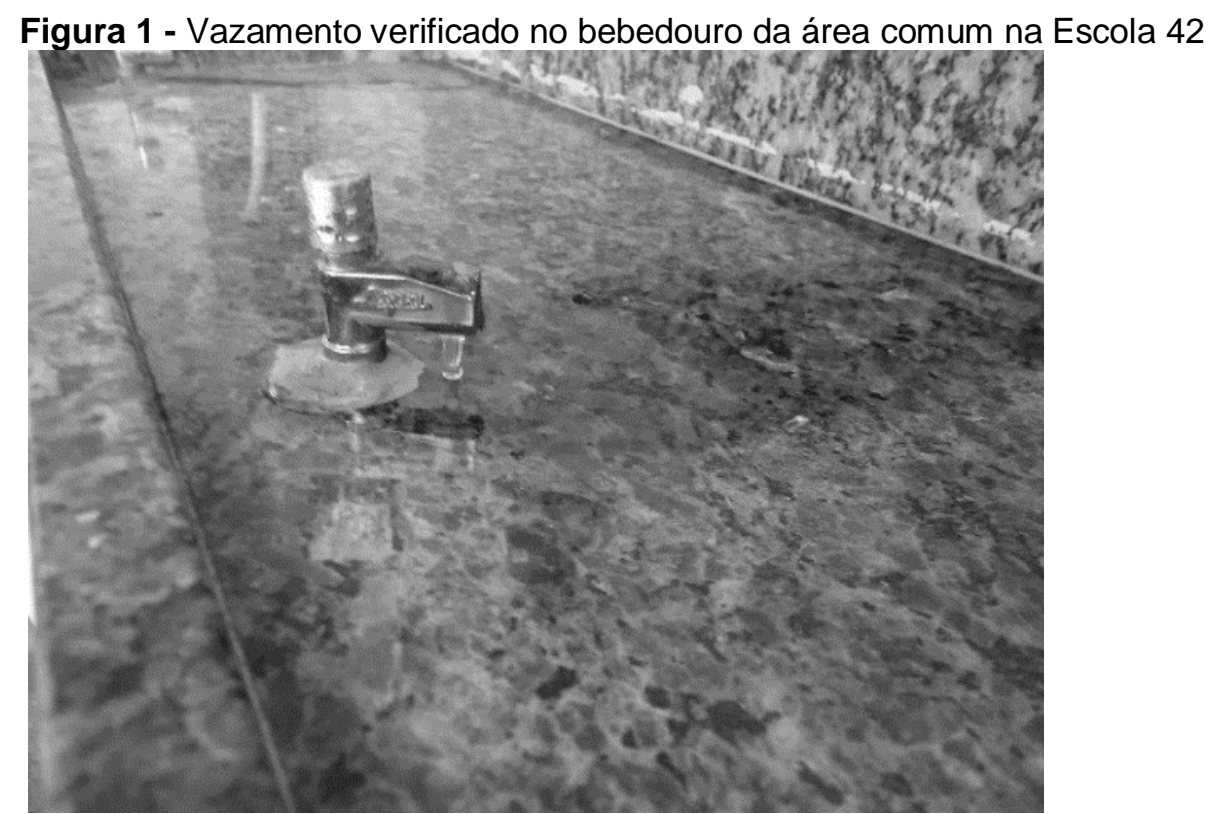


Figura 2 - Vazamento verificado no registro do chuveiro do banheiro masculino dos funcionários na Escola 42

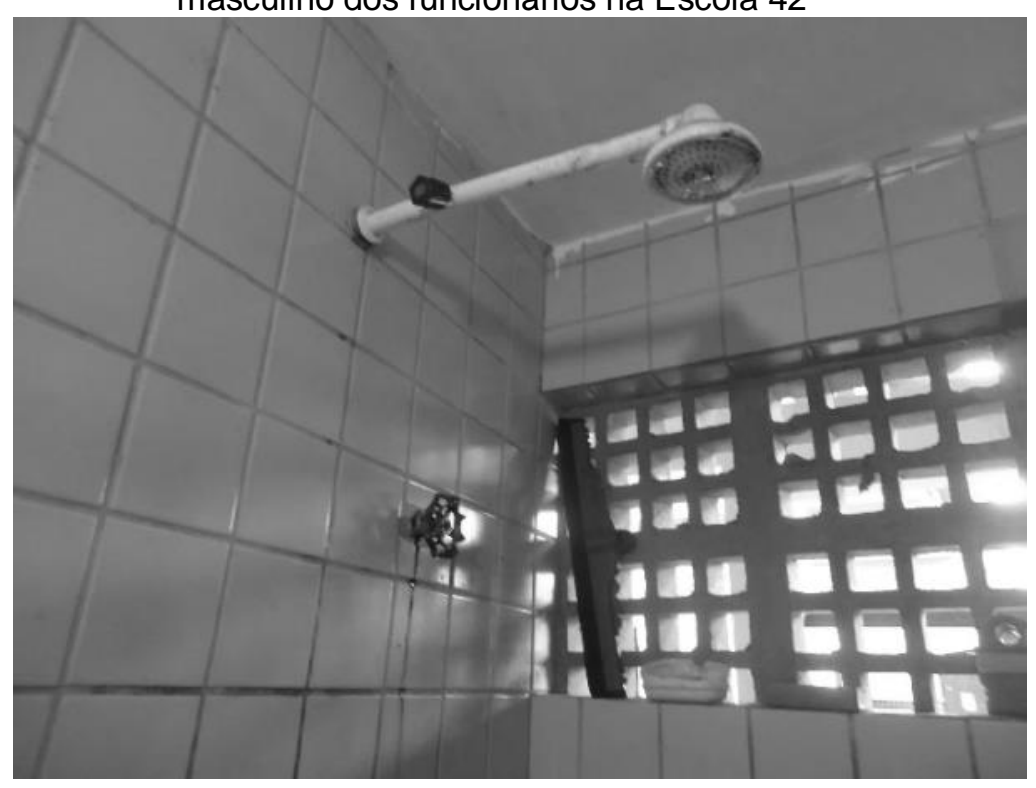

O IC da Escola 42 pode ser considerado alto, por sua vez o IC da Escola 82 pode ser considerado baixo, uma vez que Oliveira (2013) baseada em dados publicados pelo Relatório de Desenvolvimento Humano indica, como bom, um indicador de consumo entre 10 e 20 L/aluno/dia. Para analisar o índice de percepção (IU), foram utilizados dois tipos de gráfico, sendo eles o gráfico radar que agrupa o IU por ambiente e o gráfico de barras, que faz a análise da percepção total por escola. Para melhor avaliar o índice de percepção dos usuários, as atividades consumidoras de água foram divididas em quatro ambientes distintos, sendo eles: banheiros, cozinha, área interna e área externa, como mostram os Gráficos 1 e 2. Para cada ambiente foram aplicados os questionários, respondidos por alunos e funcionários. No total, 103 pessoas da Escola 42 e 44 pessoas da Escola 82 foram entrevistadas, representando aproximadamente $15 \%$ da população total. 
Gráfico 1 - Índice da percepção dos usuários da Escola 42 Índice de percepção por ambiente

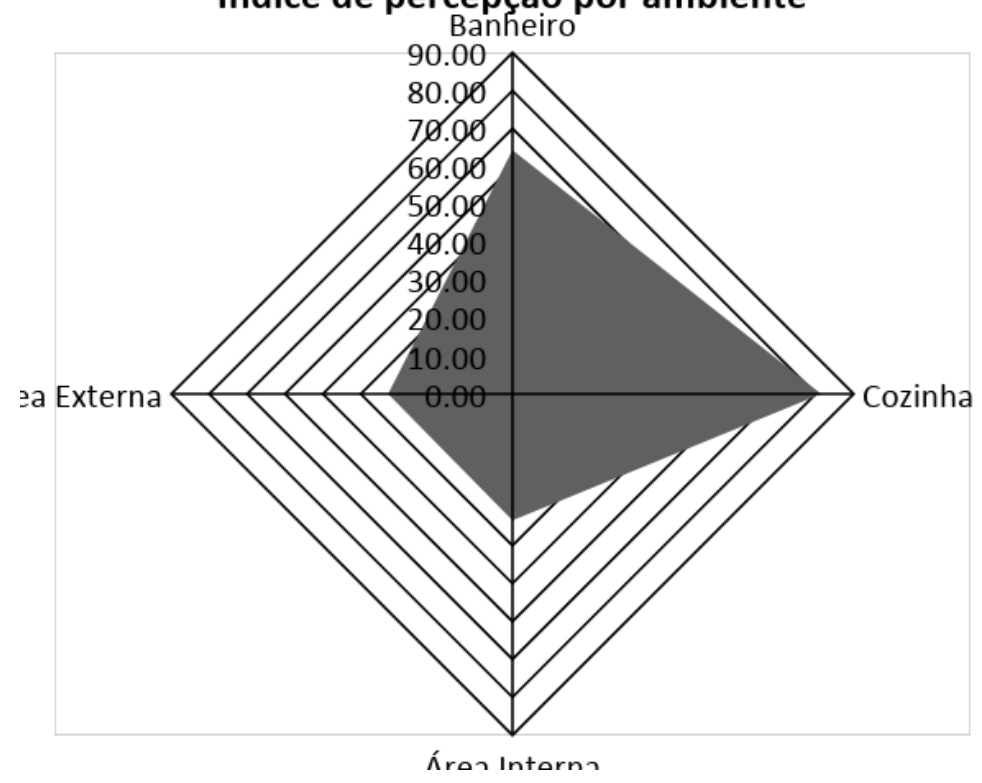

Gráfico 2- Índice da percepção dos usuários da Escola 82 Índice de perceção por ambiente

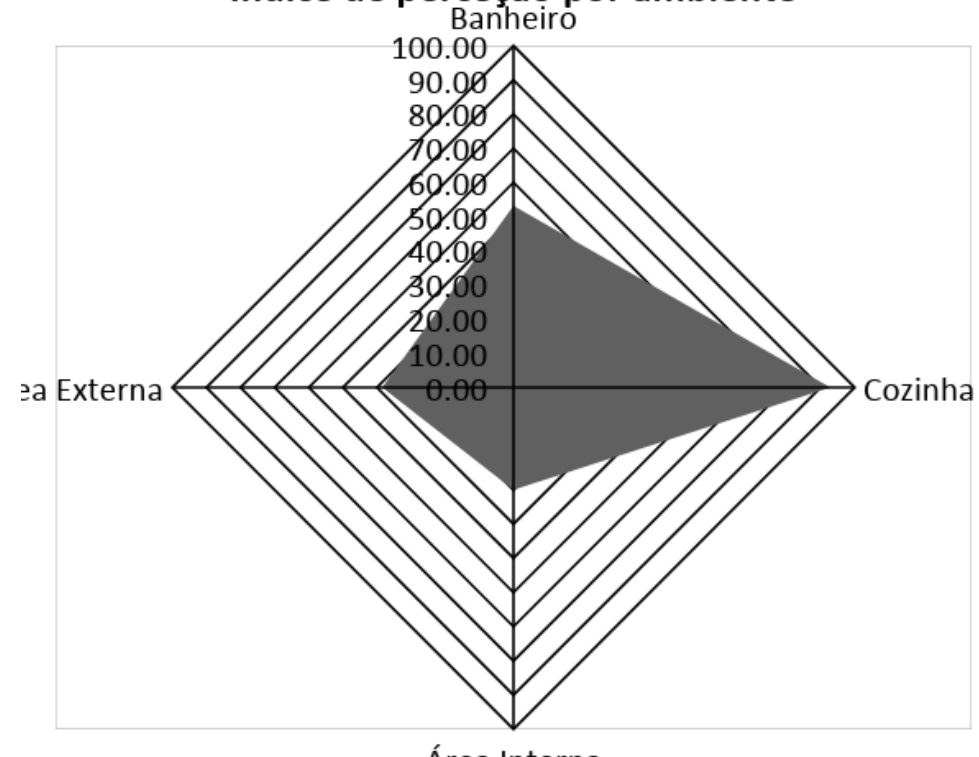

Apesar das escolas estudadas apresentarem tipologias e indicadores de consumo diferentes, os resultados obtidos mostraram-se semelhantes. Ao analisar os gráficos, é possível perceber que as atividades realizadas nos banheiros apontam para o segundo maior índice de percepção dos usuários quanto ao uso racional da água, que, segundo a literatura, é o ambiente mais consumidor de água, com $64,27 \%$ da percepção total para a Escola 42 e aproximadamente 53,19\% para a Escola 82. 
De acordo com os questionários, grande parcela da população total de alunos da Escola 42 toma banho na escola devido aos longos períodos de permanência no ambiente escolar, gastando em média 10 minutos por pessoa para a realização da atividade. Vazamentos são vistos com frequência e muitos dos alunos entrevistados não demonstraram comunicar à coordenação para que o reparo possa ser realizado, vindo a contribuir com a perda de alguns pontos do índice de percepção.

Já na Escola 82, é possível observar que a maior parte da população total não toma banho na escola por se tratar de regime regular e vazamentos não são vistos com frequência.

Não há manutenção preventiva das instalações hidrossanitárias nas duas escolas, existindo apenas manutenção corretiva.

Por ser o segundo maior consumidor de água nas escolas, devido ao constante preparo de refeições e limpeza, tanto das louças quanto do piso, o ambiente cozinha torna-se potencial desperdiçador, contribuindo significativamente no consumo total de cada escola, principalmente em razão do número de refeições realizadas nas escolas estudadas. Contudo, nas duas escolas analisadas, as atividades consumidoras de água no ambiente cozinha apresentaram os maiores índices de percepção dos usuários.

Em ambas as escolas o descongelamento de carnes e frios é feito sem o emprego de água. A lavagem de frutas e hortaliças não é feita em água corrente e as louças são lavadas com a torneira fechada com enxágue em água corrente. Porém, as louças são lavadas no mínimo três vezes por dia em cada escola, contribuindo consideravelmente com o consumo de água mensal. O piso é lavado com o auxílio de balde, rodo e vassoura.

Os índices de percepção para as áreas internas e externas apresentam-se com valores muito baixos, correspondendo a menos de $40 \%$ do total para cada ambiente. Apesar disso, os índices apresentados pela Escola 82 apontam para utilização mais racional da água se comparados aos da Escola 42. A área interna, correspondente às salas de aula e de professores, é higienizada semestralmente nas duas escolas. Quanto à área externa, que inclui área comum e de circulação, verifica-se uma pequena diferença entre as escolas. Enquanto a Escola 82 realiza a limpeza semestralmente, a Escola 42 desempenha a mesma função semanalmente. Por esse motivo, a percepção avaliada na Escola 82 apresenta-se maior, com 38,46\% do total, enquanto na Escola 42 a percepção encontrada foi de apenas 32,81 \%. Deve- 
se atentar também para a rega de jardim que é realizada nas duas escolas. No entanto, o consumo apresentado nesses ambientes não apresenta impactos significativos nos dados porque a limpeza com água é realizada poucas vezes se comparada com os outros ambientes.

A reutilização da água proveniente dos aparelhos de ar condicionado ainda não é feita em nenhuma das escolas analisadas, fazendo com que ela seja descartada antes da coleta para aplicação em outra atividade consumidora. $O$ índice de percepção (IU) aferido para cada escola foi de 64,11\% e 64,49\% para as Escolas 42 e 82, respectivamente, como mostram os Gráficos 3 e 4.

Gráfico 3 - Índice de percepção da Escola 42 Índice de percepção da escola

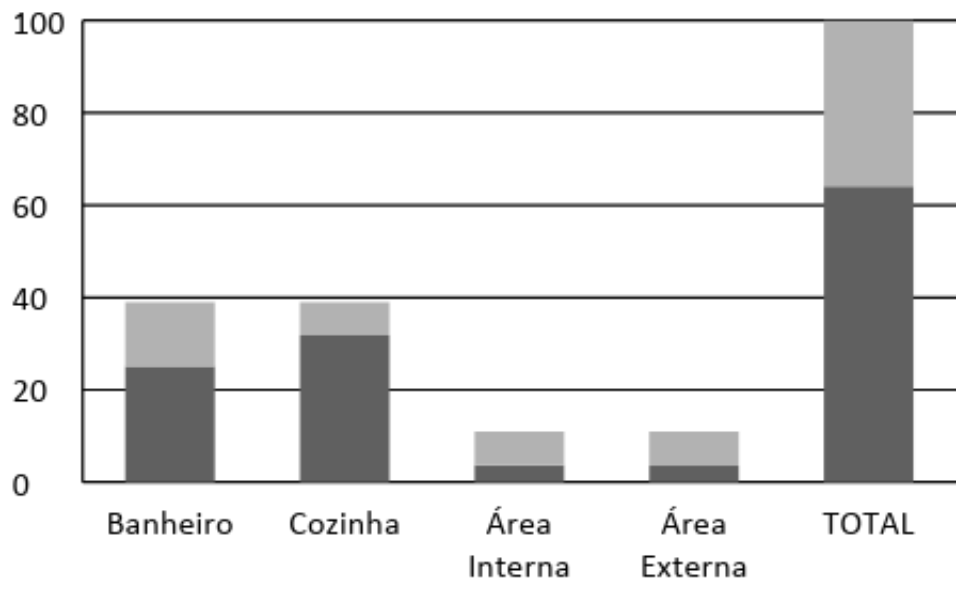

Gráfico 4 - Índice de percepção da Escola 82 Índice de percepção da escola

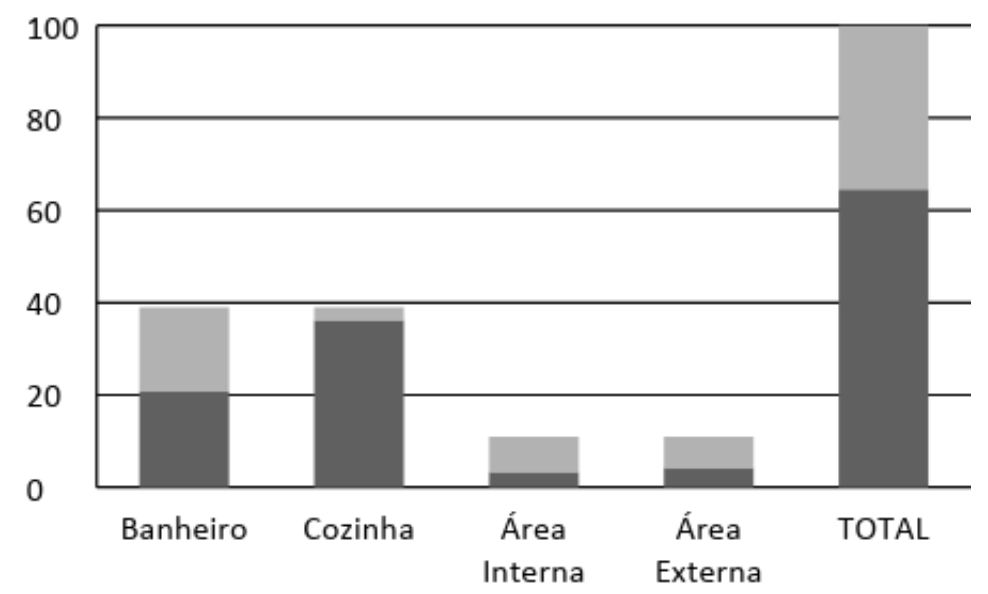


Os IU apontados pelas escolas em questão apresentam-se médios, revelando a forte presença de atividades desperdiçadoras de água nas escolas. Ao comparar os resultados obtidos neste estudo com o resultado apresentado por Nunes (2015) de $45,96 \%$ e Soares (2016) de 67,95\%, é possível perceber resultados bem próximos.

Observa-se que nas escolas estudadas por Nunes (2015) e Soares (2016), os alunos não foram investigados. Ademais, todos os pontos de consumo de água foram mapeados através da instalação de hidrômetros para medição de água setorizada, o que permitia a detecção de vazamentos aparentes, tornando seu reparo mais rápido e, consequentemente, diminuindo o desperdício de água.

Portanto, para estabelecer melhores relações comparativas entre as análises deste trabalho e dos trabalhos de Ywashima (2005), Nunes (2015) e Soares (2016), seria necessário um estudo completo do sistema hidráulico de cada escola, a fim de avaliar outros aspectos, como a quantificação de perdas por vazamentos e o monitoramento do consumo setorizado.

\section{CONCLUSÕES}

O presente trabalho expressa os resultados obtidos dos índices de percepção dos usuários para o uso racional da água de duas escolas públicas estaduais, em Recife/PE, com base no consumo do ano de 2016, sendo possível perceber que os maiores índices de percepção nos edifícios escolares dão-se nas atividades desempenhadas nas cozinhas, enquanto o menor índice foi aferido para a área interna (Escola 82) e área externa (Escola 42).

Os resultados mostram que, em geral, a percepção dos usuários para o uso racional pode ser melhorada, reforçando que muitas atividades são realizadas de maneira desperdiçadora. A partir dos valores encontrados, é possível apontar algumas medidas de sensibilização aos usuários de forma direcionada a cada ambiente, de maneira que as atividades racionais sejam vistas de forma prioritária.

Portanto, medidas de educação ambiental podem ser tomadas nos banheiros e cozinhas, por exemplo, é sugerido realizar ações educativas voltadas aos usuários para conscientização do uso racional da água. É possível ainda haver investimentos em equipamentos hidrossanitários com tecnologia poupadora de água. 
Pode-se ainda avaliar as possibilidades de instalação de um reservatório para captação de águas pluviais e reutilização das águas cinza, diminuindo a demanda diária das descargas sanitárias e dos mictórios, se houver.

Nas áreas internas e externas, propõe-se orientar os agentes de serviço a evitarem a limpeza dos ambientes com lavagem empregando água sempre que possível, substituindo o uso da mangueira e do balde com rodo pela utilização apenas do balde e pano para a limpeza dos pisos. Além disso, a água proveniente dos apareIhos de ar condicionado poderia ser coletada com a finalidade de reutilizá-la em atividades que não exigem águas nobres, como a rega de jardim e a lavagem das áreas de circulação.

É importante perceber que as condições dos aparelhos hidrossanitários podem interferir no consumo mensal de cada escola, podendo ser influenciado por fatores externos, como a leitura equivocada do hidrômetro - ou a falta de calibração do mesmo - e existência de vazamentos não detectáveis nas tubulações. Por isso, a manutenção preventiva das instalações hidrossanitárias se faz extremamente necessária.

Faz-se necessário, ainda, a efetivação de campanhas educativas nas escolas, para que cresça neste ambiente o compromisso social com as questões ambientais não somente por parte dos alunos, mas que englobe toda comunidade escolar.

O estudo direcionado ao consumo de água através da análise do índice de percepção dos usuários nos ambientes escolares visa à diminuição do desperdício desse insumo, que se apresenta alto nesta tipologia de edificação. Portanto, é fundamental que haja uma política pública voltada ao ambiente escolar para que seja determinado um Programa de Conservação da Água, garantindo a continuidade da utilização dos recursos hídricos com a minimização dos impactos ambientais.

\section{REFERÊNCIAS}

ANA. Conjuntura dos recursos hídricos no Brasil: Informe 2014 . Brasília, p.29, 2015.

GONÇALVES, O.; ILHA, M.; AMORIM, S.; PEDROSO, L. Indicadores de uso racional de água para escolas de ensino fundamental e médio. Ambiente Construído, Porto Alegre, v.5, n.3, p.35-48, jul/set, 2005.

MELO, N. A.; SALLA, M. R.; OLIVEIRA, F. R. G. de; FRASSON, V. M., Consumo de água e percepção dos usuários sobre o uso racional de água em escolas estaduais do Triângulo Mineiro. Ciência \& Engenharia, v.23, n.2, p.01-09, jul/dez, 2014. 
NUNES, L. G. C. F. Indicadores de Consumo de Água, em uma Escola Estadual de Recife-PE. Monografia (Graduação) - Escola Politécnica da Universidade de Pernambuco. Recife, PE. 2015.

NUNES, L. G. C. F.; WANDERLEY, T. R. de B.; SILVA, S. R. Indicadores de consumo de água, vazamentos e perdas: estudo de caso das escolas públicas do Recife. Revista Científica ANAP Brasil, v. 10, p.10-20, 2017.

NUNES, L. G. C. F. Plano de conservação de água: escolas públicas estaduais da cidade do Recife. Dissertação (Mestrado) - Escola Politécnica da Universidade de Pernambuco. Recife, PE. 2018, $154 f$.

OLIVEIRA, L. H.; GONÇALVES, O. M. Metodologia para a implantação de programa de uso racional de água em edifícios. Boletim Técnico da EPUSP. Universidade de São Paulo. São Paulo, 1999.

SOARES, A. E. P. Análise do Consumo de Água em uma Escola Pública Estadual de Recife-PE. Monografia (Graduação) - Escola Politécnica da Universidade de Pernambuco. Recife, PE. 2016.

TOMAZ, P. Economia de água para empresas e residências: um estudo atualizado sobre o uso racional da água. São Paulo: Navegar Editora, 2001.

TUNDISI, J. G. Novas perspectivas para a gestão de recursos hídricos. Revista USP, São Paulo, n.70, p. 24-35, junho/agosto, 2006.

VAIRAVAMOORTHY, K; MANSOOR, M. A. M. Demand Management in developing countries. In: BUTLER, D.; ALI MEMON, F. (Ed.). Waterdemand management. London, UK: IWA Publishing, 2006.

YWASHIMA, L. Avaliação do uso da água em edifícios escolares públicos e análise e viabilidade econômica da instalação de tecnologias economizadoras nos pontos de consumo. Dissertação (Mestrado em Engenharia Civil) - Universidade Estatual de Campinas. Campinas, SP. 2005. 